\title{
Oto-Acoustic Emission and Auditory Brainstem Response Profile in Children with Speech Delay at Dr. Hasan Sadikin General Hospital Bandung
}

\author{
Liani Mulasari Gunawan, ${ }^{1}$ Wijana, ${ }^{2}$ Yuni S. Pratiwi ${ }^{3}$ \\ ${ }^{1}$ Faculty of Medicine Universitas Padjadjaran, ${ }^{2}$ Department of Otorhinolaryngology-Head and \\ Neck Faculty of Medicine, Universitas Padjadjaran/Dr. Hasan Sadikin General Hospital, Bandung, \\ ${ }^{3}$ Department of Physiology Faculty of Medicine Universitas Padjadjaran
}

\begin{abstract}
Background: Language and speech delay are the most common developmental disorders found in children. Hearing loss is the most common cause of speech delay among children. Hearing loss can be detected by subjective and objective examinations. Oto-acoustic emission (OAE) and auditory brainstem response (ABR) are objective electrophysiological examination with $100 \%$ sensitivity and $99 \%$ specificity. This study was aimed to describe OAE and ABR profile in children with speech delay at Dr. Hasan Sadikin General Hospital Bandung

Methods: This study was conducted in 2014 used the descriptive cross-sectional design with a total sampling of 333 medical records of children diagnosed with speech delay with inclusion criteria patients aged 1-5 years at the Hearing Disorders Clinic of Otorhinolaryngology-Head and Neck Surgery Policlinic at Dr. Hasan Sadikin General Hospital Bandung during the period of 2011-2012.

Results: Out of all of the samples, there were 176 boys (52.9\%) and 157 girls (47.1\%). Most of children aged 24-35 months. Eighty children (24\%) with normal hearing and 253 children (76\%) with hearing loss. Hearing loss with Sensorineural hearing loss (SNHL) type most occured at the profound degree with 244 cases.
\end{abstract}

Conclusions: Hearing loss is the most common cause of speech delay in children. Speech delay can be prevented by conducting the OAE and ABR examinations as early as possible. [AM].2016;3(2):265-8]

Keywords: Auditory brainstem response examination, hearing loss, oto-acoustic emission examination, speech delay

\section{Introduction}

Language and speech delay are the most common developmental disorders found in children. $^{1,2}$ Speech and language in children can give negative impacts to the socialisation, personality, behaviour and school attainment. These disorders are experienced by 5-8\% preschool age children. In Indonesia prevalence of speech delay in children is between $5-10 \%$ in school age children. ${ }^{3-5}$

Speech and language disorders are disorders or delay in children in speaking or using language in the daily life. Hearing loss is one of the most common causes of the speech delay. 6,7 The Joint Committee on Infant Hearing (JCIH) decided that hearing loss in children should have been detected at the age of three months and the proper intervention is started before six months or less. ${ }^{8}$ This priority is in concert with the national initiative. It is shown in the result of a study conducted by Yoshinaga-Itano et al. ${ }^{9}$

Hearing loss can be detected by subjective and objective examinations. Oto-acoustic emission (OAE) and auditory brainstem response (ABR) are objective electrophysiological examinations with 100\% sensitivity and 99\% specificity. For children, $\mathrm{OAE}$ is an ideal screening from the ear to the cochlea, since it can examine babies from the age of one day in a fast, easy, and unpainful way. The ABR examination measures the brainstem auditory pathway and can estimate the threshold of hearing and the type of hearing loss (conductive, sensorineural, or mixed). ${ }^{1,6}$ This study was aimed to describe $\mathrm{OAE}$ and $\mathrm{ABR}$ profile in children with speech delay at Dr. Hasan Sadikin General Hospital Bandung.

Correspondence: Liani Mulasari Gunawan, Faculty of Medicine, Universitas Padjadjaran, Jalan Raya Bandung-Sumedang Km.21, Jatinangor, Sumedang, Indonesia, Phone: +62811958787 Email: lianimulasari@gmail.com 
Table 1 Incidence of Hearing Loss.

\begin{tabular}{ccccccc}
\hline \multirow{2}{*}{ Age (months) } & \multicolumn{3}{c}{ Normal } & \multicolumn{3}{c}{ Hearing Loss } \\
\cline { 2 - 7 } & Boy(s) & Girl(s) & Total & Boy(s) & Girl(s) & Total \\
\hline $12-23$ & 2 & 0 & 2 & 12 & 10 & 22 \\
$24-35$ & 25 & 8 & 33 & 56 & 45 & 101 \\
$36-47$ & 16 & 9 & 25 & 27 & 45 & 72 \\
$48-59$ & 12 & 2 & 14 & 12 & 22 & 34 \\
$>60$ & 2 & 4 & 6 & 12 & 12 & 24 \\
Total & 57 & 23 & 80 & 119 & 134 & 253 \\
\hline
\end{tabular}

Table 2 Results of Oto-Acoustic Emission (OAE) Examination .

\begin{tabular}{lccc}
\hline & Result & Number & \% \\
\hline Pass & 80 & 24 \\
Refer & 253 & 76 \\
Total & 333 & 100 \\
\hline
\end{tabular}

\section{Methods}

This study was conducted in 2014 using a descriptive cross-sectional design to 333 medical records of children diagnosed with speech delay at the Hearing Disorders Clinic of Otorhinolaryngology-Head and Neck Surgery
Policlinic at Dr. Hasan Sadikin General Hospital Bandung during the period of 2011-2012. The inclusion criteria were medical record data of speech delay patients aged 1-5 years and exclusion criteria were patients with craniofacial, congenital anomali and other problems.

Table 3 Results of Auditory Brainstem Response (ABR) Examination

\begin{tabular}{|c|c|c|c|c|c|c|}
\hline \multirow{2}{*}{ Type of Hearing } & \multirow{2}{*}{$\begin{array}{c}\text { Degree of } \\
\text { Hearing }\end{array}$} & \multirow{2}{*}{$\begin{array}{l}\text { Threshold of } \\
\text { Hearing (dB) }\end{array}$} & \multicolumn{2}{|c|}{ Right Ear } & \multicolumn{2}{|c|}{ Left Ear } \\
\hline & & & $\mathbf{n}$ & $\%$ & $\mathbf{n}$ & $\%$ \\
\hline Normal & Normal & $0-25$ & 80 & 24 & 80 & 24 \\
\hline \multirow[t]{4}{*}{ SNHL } & Mild & $26-40$ & 10 & 3 & 10 & 3 \\
\hline & Moderate & $41-60$ & 7 & 2,1 & 13 & 3.9 \\
\hline & Severe & $61-80$ & 72 & 21.6 & 75 & 22.5 \\
\hline & Profound & 81 or $>$ & 155 & 46.6 & 146 & 43.9 \\
\hline \multirow[t]{4}{*}{ CHL } & Mild & $26-40$ & 4 & 1.2 & 3 & 0.9 \\
\hline & Moderate & $41-60$ & 0 & 0 & 0 & 0 \\
\hline & Severe & $61-80$ & 2 & 0.6 & 1 & 0.3 \\
\hline & Profound & 81 or $>$ & 3 & 0.9 & 5 & 1.5 \\
\hline \multirow[t]{4}{*}{ MHL } & Mild & $26-40$ & 0 & 0 & 0 & 0 \\
\hline & Moderate & $41-60$ & 0 & 0 & 0 & 0 \\
\hline & Severe & $61-80$ & 0 & 0 & 0 & 0 \\
\hline & Profound & 81 or $>$ & 0 & 0 & 0 & 0 \\
\hline Total & & & 333 & $100 \%$ & 333 & $100 \%$ \\
\hline
\end{tabular}




\section{Results}

Out of all of the samples, there were 176 boys (52.9\%) and 157 girls (47.1\%). Most of children aged 24-35 months. Based on the result of OAE examination there were 80 children (24\%) with normal hearing (pass in examination) and 253 children (76\%) with hearing loss (refer in examination).

Based on the result of ABR examination, hearing loss with Sensorineural hearing loss (SNHL) type most occured at the profound degree with 244 cases.

\section{Discussion}

It is shown that the least number of patients were the one-year-old patients, meaning that the parents had not realized the hearing loss of their children (Table 1). This might be caused by the lack of awareness and knowledge of the parents regarding the children's reaction to sound and the impact of hearing in children. If the children were diagnosed with hearing loss before the age of 6 months, those children would still have bigger chances to be able to speak and communicate optimally, since they would obtain earlier managements. This is shown in the result of a study conducted by Yoshinaga-Itano etal. ${ }^{9}$ which stated that earlier identification and management of permanent childhood hearing loss is known to result in improved developmental outcomes, children with hearing loss who got intervention before six months of age got improved results in language at 3 years of age.

From the results of $\mathrm{OAE}$ and $\mathrm{ABR}$ examinations, the ratio of children with hearing loss and normal children is 3:1. There were 253 children (75.98\%) with speech delay who got "refer" or "not pass" in their OAE examination, which means that hearing loss is the most common cause. The results of ABR examination is categorized based on the degree of hearing loss and location of the disorder, whether at the left or right ear. ${ }^{10}$ The most frequently found hearing loss was the profound hearing loss, in which the children were not able to hear a loud sound from a nearby place.

The hearing loss which most commonly occurred was the SNHL i.e. 244 cases and Conductive hearing loss (CHL) i.e 9 cases. The SNHL is the sensorineural hearing loss, i.e. a disorder at the cochlea or the inner ear. Children are indeed identified with SNHL, a variety of diagnostic tests can be recommended depending on the patient's history and physical examination. ${ }^{11}$ For infants/children with profound hearing loss, probability exists by use of hearing aids or cochlear implantation (CI) and speech therapy. Children with mild hearing loss should also be monitored for developmental and behavioral problems (attention deficit/hyperactivity disorder, autism, and learning disabilities), speech therapy and use of hearing aids. Speech and language disorders seem to have more impact on motor performance than only language disorders, and it seems that when speech production is affected, motor problems are more pronounced. The results support the need to give early and more attention to motor development. Moreover, special attention should be given to children with speech and language disorders. ${ }^{12}$

As a conclusion, this study found that hearing loss is the most common cause of speech delay in children (76\%). Speech delay can be prevented by conducting the OAE and ABR examinations as early as possible.

\section{References}

1. American Speech-Language-Hearing Association. Preferred practice patterns for the profession of speech-language pathology.2004 [cited 2013 October 12]. Available from: www.asha.org/ uploadedFiles/PP2004-00191.Pdf

2. American Academy of Pediatrics, Committee on Practice and Ambulatory Medicine and Bright Futures Steering Committee. Recommendations for preventive pediatric health care. Pediatrics. 2007;120(6):1376

3. Law J, Garrett Z, Nye C. Speech and language therapy intervention for children with primary speech and language delay or disorder. Cochrane Database Syst Rev. 2003;(3):CD004110

4. Nelson HD, Nygren P, Walker M, Panoscha R. Screening for speech and language delay in preschool children: systematic evidence review for the US Preventive Service Task Force. Pediatric.2006;117(2):e298-319

5. Gunawan G, Destiana R, Rusmil K. Gambaran perkembangan bicara dan bahasa anak usia 0-3

6. Futures Steering Committee and Medical Home Initiatives for tahun. Sari Pediatri. 2011;13(1):21-5.

7. Council on Children with Disabilities; Section on Developmental Behavioral Pediatrics; Bright Children with Special 
Needs Project Advisory Committee. Identifying infants and young children with developmental disorders in the medical home: an algorithm for developmental surveillance and screening. Pediatrics. 2006:118(1):405-20.

8. Soepardi EA, Iskandar N, Bashiruddin J, Rastuti RD, editors. Buku ajar ilmu kesehatan-telinga hidung tenggorok kepala \& leher. $6^{\text {th }}$ ed. Jakarta: Fakultas Kedokteran Universitas Indonesia, 2007.p.31-40

9. American Academy of Pediatrics; Joint Committee on Infant Hearing. Year 2007 position statement: principles and guidelines for early hearing detection and intervention programs. Pediatrics. 2007;120(4):898 -921

10. Yoshinaga-Itano C, Sedey AL, Coulter DK,
Mehl AL. Language of early- and lateridentified children with hearing loss. Pediatrics. 1998:102(5):1161-71.

11. Moeller MP, White KR, Shisler L. Primary care physicians' knowledge, attitudes, and practices related to newborn hearing screening. Pediatrics. 2006;118(4):13571370.

12. Harlor JR ADB, Bower C. Hearing assessment in infants and children: recommendations beyond neonatal screening. Pediatrics. 2009;124(4):125263.

13. Visscher C, Houwen S, Scherder EJ, Moolenaar B, Hartman E. Motor profile of children with developmental speech and language disorders. Pediatrics. 2007;120(1):e158-63. 